\title{
Seismic reflection data processing in active volcanic areas: an application to Campi Flegrei and Somma Vesuvius offshore (Southern Italy)
}

\author{
Pier Paolo G. Bruno $\left({ }^{1}\right)$, Vincenzo Di Fiore $\left(^{2}\right)$ and Antonio Rapolla $\left({ }^{2}\right)$ \\ (1) Osservatorio Vesuviano, Istituto Nazionale di Geofisica e Vulcanologia, Napoli, Italy \\ (2) Dipartimento di Scienze della Terra, Università degli Studi di Napoli «Federico II», Napoli, Italy
}

\begin{abstract}
The Campanian volcanism develops near the sea. Therefore, the geophysical study of the marine environment is a key to a better understanding of the tectonic evolution and the origin of volcanism in the area. An abundance of high quality seismic data in the marine sector, where little direct information is available, is critical to the study of Campanian volcanism. This paper concerns the reprocessing of a seismic reflection dataset acquired in Naples Bay and processed during 1973. Even though the overall data quality was high for that time, of course their acquisition technological limits have been overcome by the new processing. Our reprocessing aimed at: 1) reduction of random noise in the data; 2) removal of unwanted coherent events; 3 ) reduction of spatial aliasing by means of trace interpolation on Commod Shot Point (CSP) gathering; 4) improvement of resolution of the seismic wavelet with spiking deconvolution algorithms and finally 5) reposition of reflectors in their correct locations in the spaceTWT domain by means of dip moveout and post-stack time migration. A comparison between the new and old data shows that the new sections are characterized by a much higher $\mathrm{S} / \mathrm{N}$ ratio. Diffraction hyperbole has been collapsed. Reverberations, ghosts and multiples have been removed or greatly attenuated, especially between the reflectors of interest, allowing us to follow them with more detail and with greater continuity. Furthermore, data resolution has been boosted by the reprocessing, allowing the interpreter to evaluate reflector position and continuity in greater detail. The reinterpretation phase of such lines, that is already in an advanced stage, will therefore allow us to gain new insights into the structural setting of the bay, with the aim of exploring the connection between tectonics and volcanism.
\end{abstract}

Key words marine geophysics - seismic reflection Naples Bay - Campi Flegrei - Somma-Vesuvius

\section{Introduction}

This paper concerns the reprocessing of a seismic reflection dataset acquired in Naples Bay (NB) by OGS (Istituto Nazionale di Oceanografia

Mailing address: Prof. Antonio Rapolla, Dipartimento di Scienze della Terra, Università degli Studi di Napoli «Federico II», Largo San Marcellino 10, 80138 Napoli, Italy; e-mail: rapolla@unina.it e Geofisica Sperimentale) during 1973 (Finetti and Morelli, 1974) in order to acquire new data in a vital area for the understanding of the local active volcanism. This area, which experienced a regional extension during the Plio-Quaternary is of great importance because it is the site of active volcanism: the presence of volcanoes with geological and historical records of very explosive events (such as ignimbrites and Plinian eruptions) in a densely populated territory, implies a high risk. Naturally, explosive volcanic activity also includes a strong and very frequent seismic activity, even if limited to localized areas, such as Pozzuoli town. Although the recent 
seismic crises of 1970-1972 and 1982-1984 in Campi Flegrei (CF) did not culminate in a volcanic eruption, they caused extensive damage, and the evacuation of an entire district of Pozzuoli Town (Rione Terra: De Stefano et al., 1988).

The Campanian volcanism develops near the sea; Procida and Ischia are volcanic islands. Bruno et al. (2002) showed that the remnant of a once larger volcanic complex extended to the western offshore of Ischia Island. Somma Vesuvius (SV) complex is located on the coastline, at about $10 \mathrm{~km}$ to the $\mathrm{SW}$ of the city of Naples (fig. 1). Probably this volcano started its activity in a shallow water environment whereas CF volcanic field constitutes a promontory located at about $10 \mathrm{~km}$ to the West of Naples.
Morphological, geophysical and geological data suggest that the CF caldera continues in the Gulf of Pozzuoli (GP) (Agip, 1987; Rosi and Sbrana, 1987; Orsi et al., 1996; Florio et al., 1997). Therefore, the geophysical study of the marine environment is a key to better understanding the tectonic evolution and the origin of volcanism in the area with clear spin-off on the seismic and volcanic hazard.

An abundance of high quality geophysical data (and among them seismic data, which allow the highest resolution) is critical to the study of marine environments where little direct information is available. Unfortunately, high quality geophysical data are missing in the NB. The spatial resolution of the available aeromagnetic and marine gravity data collected in

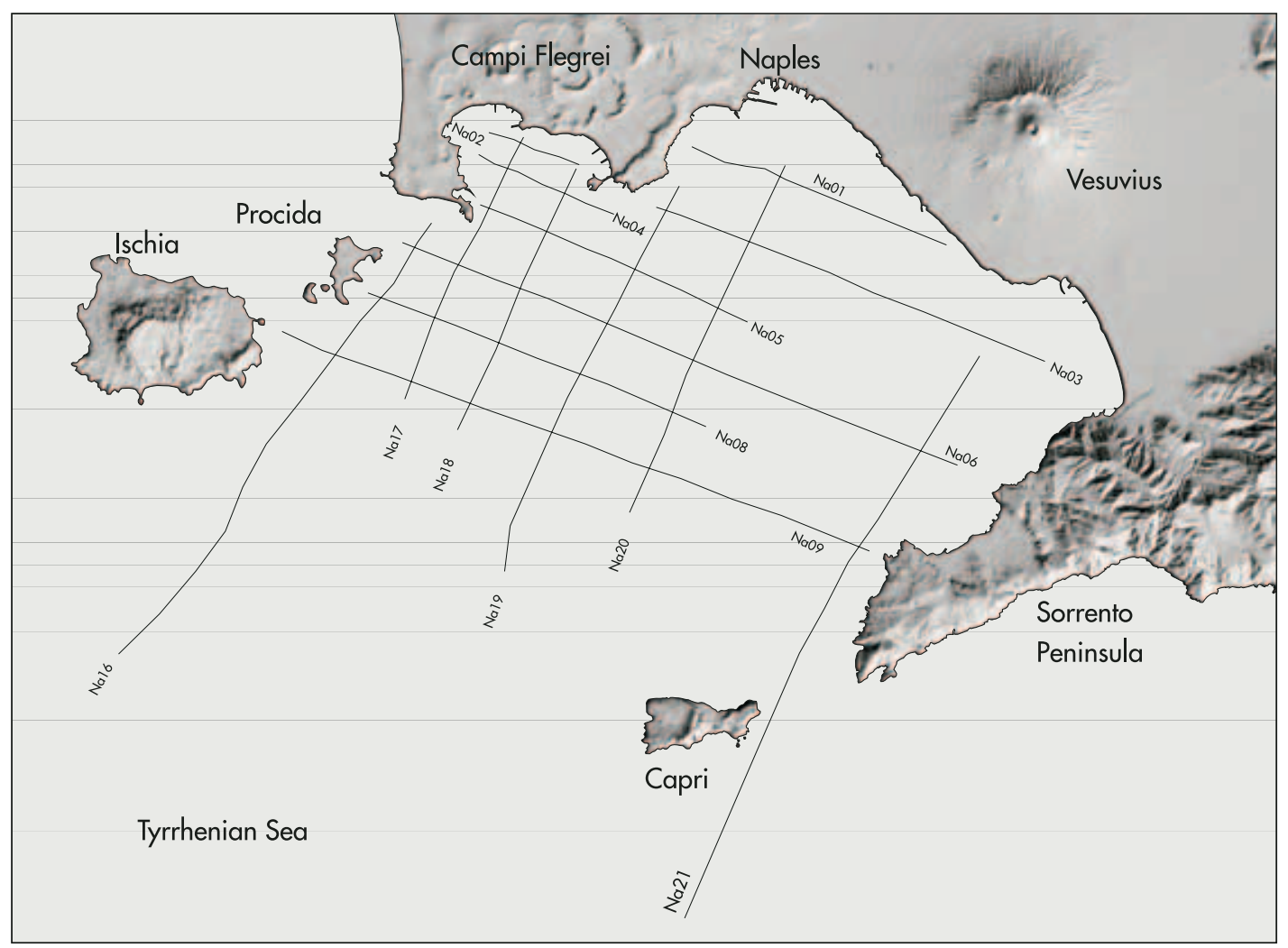

Fig. 1. Location of the seismic lines in the Gulf of Naples. 
the bay (Agip, 1982) is insufficient. More recent and detailed potential field data acquisition only concerned limited sectors of the bay.

At present, the only deep seismic dataset available in the area was collected by OGS (Istituto Nazionale di Oceanografia e Geofisica Sperimentale) during 1973. Deep seismic reflection data allow very high detail, but the acquisition is quite expensive, and often it is not affordable for public research institutions. Indeed, more recent seismic data collected in $\mathrm{NB}$ are, in most cases, high resolution - single channel sparker and uniboom profiles, which allow the shallow Plio-Quaternary cover to be studied in detail, but do not penetrate deep. Therefore, fault geometry and kinematics, and in some cases the tectonic involvement of the deep geological units are hypothetical. For all these reasons the sea environment geology in the Gulf of Naples is less known than the onshore areas. To gain more information on the deep part of NB, near the GP, we decided to reprocess the 1973 OGS seismic dataset. Reprocessing old seismic data has become a standard in the oil industry since technological advances bring notable improvements to the data in terms of Signal-to-Noise $(\mathrm{S} / \mathrm{N})$ ratio, allowing the interpreter to obtain new information at low cost.

\section{Geological settings}

NB is the submerged sector of the Campanian Plain, a Quaternary graben bordered by Mesozoic carbonates. The plain and the overlooking Tyrrhenian Sea originated from stretching and thinning of the continental crust due to the rotation the Italian peninsula (Patacca et al., 1990). A Pliocene distension phase (Sgrosso, 1998) created the conditions for magma uprising in the area. The active volcanoes develop along the coast with the presence of two main volcanic centres: $\mathrm{CF}$ and $\mathrm{SV}$.

$\mathrm{CF}$ are a volcanic field developed within a nested caldera (fig. 1) which was created by two large ignimbritic eruptions that produced widespread ash-flow deposits: the "Campanian ignimbrite» (CI) at about 34000 a b.p., and the «Neapolitan Yellow Tuff» (NYT) about 12000 years ago. After the NYT eruption, the caldera was invaded by the sea (Scandone et al., 1991). Subsequent volcanic activity emplaced only within the caldera structure, frequently along its rims and sometimes involving intra-calderic collapses (Lirer et al., 1987). The erupted products range in composition from K-basalts to alkali-trachyte and phonolite. The complex has been active since at least 47000 a b.p.

An uplift of the caldera floor already occurred between 10 and 5 ky b.p. (Cinque et al., 1985). A marine terrace (La Starza), raised to height of about $40 \mathrm{~m}$, currently borders the northern shore of the Gulf of Pozzuoli. The uplift was accompanied and followed by revived volcanic activity.

Sea-level measurements made in the ruins of a Roman market (Serapeo), built near the seashore in the town of Pozzuoli, have indicated a slow sinking of the area since Roman times. (These slow movements of the ground have been called bradyseism from the Greek «bradi» slow and «seism» movement). The Serapeo floor, had to be upraised only two centuries after its first construction, because of the sea ingression.

At the beginning of 1900, early land levelling showed that the maximum value of ground sinking was occurring in the town of Pozzuoli. This slow sinking continued until 1968. An inversion of tendency occurred during 1970-1972 and 1982-1984 with two important episodes of inflation (Berrino et al., 1984). During these periods an uplift of $170 \mathrm{~cm}$ and $182 \mathrm{~cm}$ respectively was measured at the point of maximum deformation, located in Pozzuoli town. The inflation geometry is the mirror image of the slow sinking observed until 1968; it has a circular symmetry around Pozzuoli and regularly decreases toward the margin of the caldera. A partial deflation of about $20 \mathrm{~cm}$ occurred after the 19701972 episode. About $70 \mathrm{~cm}$ have been recovered since the 1982-84 episode.

Deformation at CF seems strongly controlled by the caldera structure. Luongo et al. (1991) and Civetta et al. (1995) explain the uplift with a caldera-resurgence phenomenon, which involves both brittle and ductile deformation (Orsi et al., 1996).

Scandone et al. (1991) suggest instead that the pattern of ground deformation does not seem 
compatible with magma migration toward shallow depth, because in such case a decrease of the aerial extent of the inflation would be expected.

Contrary to the sinking phase, uplift episodes are accompanied by marked seismic activity. Earthquakes occur mostly in the coastal region around Pozzuoli, fewer deeper events occur within the bay, but they do not extend outside the border of the CF caldera (fig. 2a). Hypocenters are located between a few hundred meters and about $5 \mathrm{~km}$ depth. The maximum recorded magnitude (4.0) was observed in 1984.

Aster and Meyer (1988) made a tomographic study of the crustal structure of the caldera by a simultaneous tridimensional inversion of velocity and hypocenters of earthquakes. They found that the central part of the Pozzuoli caldera has an anomalous high $V_{p} / V_{s}$ ratio and low $V_{p}$ and $V_{s}$, indicating an incompetent highly fractured medium, saturated with water. According to this study, areas of anomalous low $V_{p} / V_{s}$ ratio occur at the borders of the caldera depression. Position of the deepest earthquakes focus delimit an inward-dipping elliptical zone, interpreted as a ring fault.

With the exception of three short-duration uplift episodes in 1989, 1994 and 2000, the last sixteen years of ground deformation at CF have been characterised by slowly descending movements. The last uplift started in early March, 2000 and reached its peak value during the following summer (fig. 2b). Accompanying the ground uplift, two swarms of low-energy earthquakes occurred on July 7 and August 22, 2000. By analysis of the first swarm, Saccorotti et al. (2002) hypothesised a direct involvement of magmatic/hydrothermal fluids in the source process. Conversely, the spectra of the August events are typical of shear failure. Location techniques applied to the August swarm allowed for the recognition of two parallel alignments trending NE-SW. This direction corresponds with that of the main focal plane obtained from fault plane solutions.

The other active volcanic complex located in the study area is the SV. Structurally, the complex is positioned at the crossing point of two regional faults with NW and SE trends (Bruno et al., 1998). SV is a stratovolcano constituted by an old apparatus (Mt. Somma) that

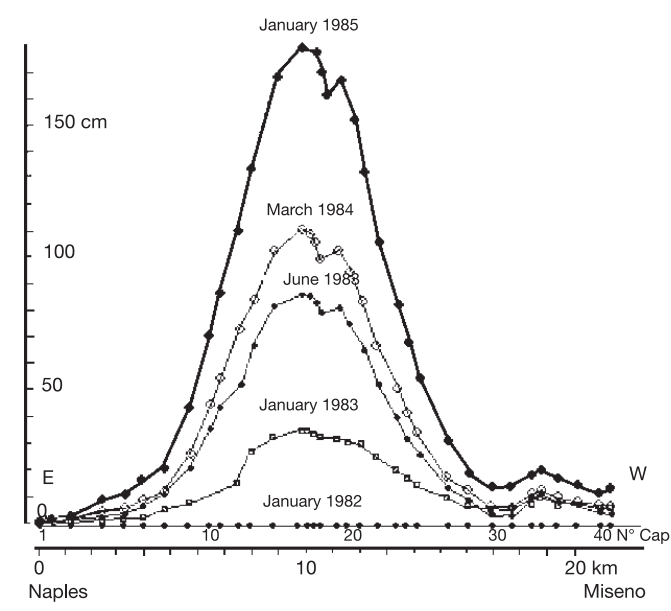

(a)

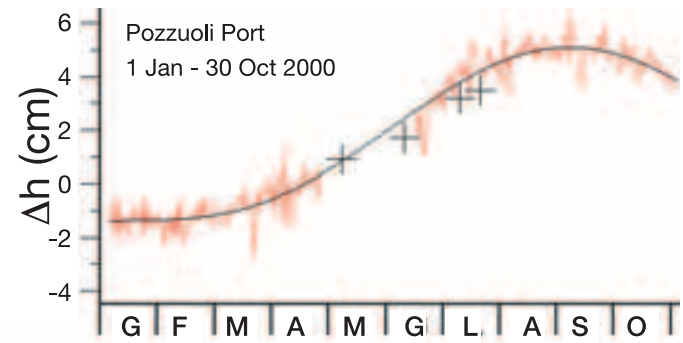

(b)

Fig. 2a,b. a) Deformation measured along a NaplesMiseno line and crosscutting Pozzuoli town (Berrino et al., 1984); b) ground level fluctuation during 2000 uplift episode deduced from a marigraphic station located at Pozzuoli Port (Vesuvian Observatory data, 2000).

includes an asymmetric caldera. The new apparatus, Mt. Vesuvius, is grown within this caldera. The more ancient outcropping products date 25 about ky (Alessio et al., 1974); these products are related to the oldest known Plinian eruption of SV (Basal pumice 19 ky b.p.), that is found above the CI deposits. Ancient SV lava samples found at a depth of $1125 \mathrm{~m}$, date about 300 $\mathrm{ky}$ : this age is possibly indicative of the beginning of SV volcanic activity. 
Mt. Somma edifice is constituted prevalently by lava. Somma morphology is the result of different collapse episodes which have determined the westward downfall of part of the mountain (Bruno and Rapolla, 1999), the sinking of the upper part of the volcano and the formation of a caldera. Such caldera records at least five collapse phases linked to Plinian eruptions (Andronico et al., 1995, 1996). The recent activity occurred prevalently in the caldera ring of the Mt. Somma.

Eruptions at SV are often characterised by both effusive and explosive activity. The effusive activity is often accompanied by pyroclastic flows and by lahar running along narrow canyons. The explosive activity, characterised by Plinian and sub-Plinian eruptions (Scandone et al., 1993), usually begins with a violent ejection of large amounts of pyroclastic products, such as pumice and ashes, followed by pyroclastic flow and surges. An example is the Plinian eruption of Pompei in 79 A.D.

Volcanic and historical records allowed the reconstruction of the history of the volcano in the last $25 \mathrm{ky}$. In particular, researchers distinguish three principal eruptive cycles (e.g., Andronico et al., 1995, 1996). The first cycle (between 25 and $11 \mathrm{ky}$ b.p.) is mainly characterized by two Plinian events. During the second cycle (11ky - 79A.D.), there were three Plinian eruption (Mercato, 7.9 ky b.p.; Avellino, 3.8 ky b.p.; Pompei, 79 A.D.) and several sub-Plinian eruptions. The third cycle (79 A.D. present) includes two or perhaps three sub-Plinian eruptions (Pollena, 472 A.D.; 512; 1631), a long strombolian activity, and more recently, mixed style eruptions (e.s. 1906 and 1944). Nowadays, Vesuvius is in a quiescent phase (Scandone et al., 1993).

Explosive volcanic activity at Vesuvius also implies the presence of seismic activity. The seismic activity of Vesuvius is characterised by swarm events that include events with large differences in magnitude. For example after the last eruption of 1944, seismic activity at Mt. Vesuvius has been characterized by about 200 events/year with magnitudes ranging between 0.4 and 3.6 (Vilardo et al., 1996). There are periods during which the number of earthquakes increases drastically: during these periods, referred to as crises, 100-150 earthquake events per month can occur (Saccorotti et al., 2002). The earthquake hypocentres are localized at depths that range from the top of the crater down to about $6 \mathrm{~km}$ b.s.l. Clustering occurs between 2 and $3 \mathrm{~km}$ b.s.l. Because of the shallow depth of the hypocentres, the events of greater magnitude can cause local damage.

\section{Data reprocessing}

The OGS seismic dataset consist of 11 profiles (fig. 1). This data set was already processed by OGS in 1973. Even though their overall quality was high for that time, they suffer acquisition technological limits that can be mainly condensed into two points: the choice (probably forced at that time) of the field recording parameters and of the energizing source. The low number of geophone groups (only 24 against 120 and more used now) limited the spatial sampling and the maximum offsets of the data, with negative repercussions on the quality of the velocity functions, particularly at high Two-Way Times (TWT). Furthermore, the use of the Flexotir source, largely utilized in the past and now abandoned by the oil industry, has certainly induced bubble effects which contributed to distort the seismic wavelet.

The old 1973 processing sequence consisted of deconvolution, band pass filtering and stacking. Such processing, especially in the CF marine sector, where the $\mathrm{S} / \mathrm{N}$ ratio is low, did not yield clear, high quality, seismic sections. Indeed, in the old seismic section, multiple reflections and diffraction hyperbolas are very frequent. Some lines of the GP are characterized by such a low $\mathrm{S} / \mathrm{N}$ ratio that it is virtually impossible to indentify any geological structure below the very shallow Quaternary drape.

Our reprocessing therefore aimed at: 1) reduction of random noise in the data; 2) removal of unwanted coherent events; 3) reduction of spatial aliasing by means of trace interpolation on Commod Shot Point (CSP) gathers; 4) improvement of resolution of the seismic wavelet with spiking deconvolution algorithms and finally 5) reposition of reflectors in their correct locations in the space-TWT domain by means of dip moveout and post-stack time migration.

In detail, our initial procedure of reprocessing consisted of data quality check and field 
geometry assignment. Trace editing aimed at detection and removal of dead or very noisy traces and spikes that may induce problems with forward Fast Fourier Transform (FFT). A top muting eliminated the first breaks (directed/ refracted arrivals) from the seismic traces. Automatic Gain Control (AGC: Sheriff and Geldart, 1995) allowed a trace normalisation. The AGC operator uses a time window of given length (in our case $500 \mathrm{~ms}$ ), which is moved down the trace sample by sample, and calculates a scale factor at each location. The scale factor is equal to the inverse of the Root Mean Square (RMS) amplitude in the window. This scalar was applied to the sample at the centre sample of the time window.

The presence of spatial aliasing is visible as parallel energy bands with a low dip in the negative halfspace in the frequency-wavenumber (FK) domain (Bracewell, 1965; Yilmaz, 1987) (see fig. 3c) that wraps around and superimposes the useful signal. In such case, a band pass filter is useless. Spatial aliasing problems were reduced by means of trace interpolation. The method used transformed the data to the Tau-P domain (Alam and Lasocki, 1981; Diebold and Stoffa, 1981), weighted each transformed sample based on a coherency measure, and then inverse transformed the data to the new spatial sampling. Trace interpolation allowed us to increase the spatial resolution on the Common Shot Point gathers (CSP) and reduce the spatial aliasing on CSP and on the final sections (fig. 3b,d).

An important part of the processing time was spent on data deconvolution. The aim was to compensate for the low resolutive wavelet of the Flexotir source and for some other undesirable effects included in the recorded earth response, such as reverberation, multiple arrivals and ghosting. Spiking pre-stack and post-stack deconvolution was applied to improve temporal resolution. Spiking deconvolution is a leastsquares inverse filter that compresses the seismic source wavelet into a zero lag spike. The filter coefficients are estimated from the auto-correlogram of the seismic trace that contains information on the source signature. Predictive deconvolution (Peacock and Treitel, 1969) attempts to predict and remove repetition in the

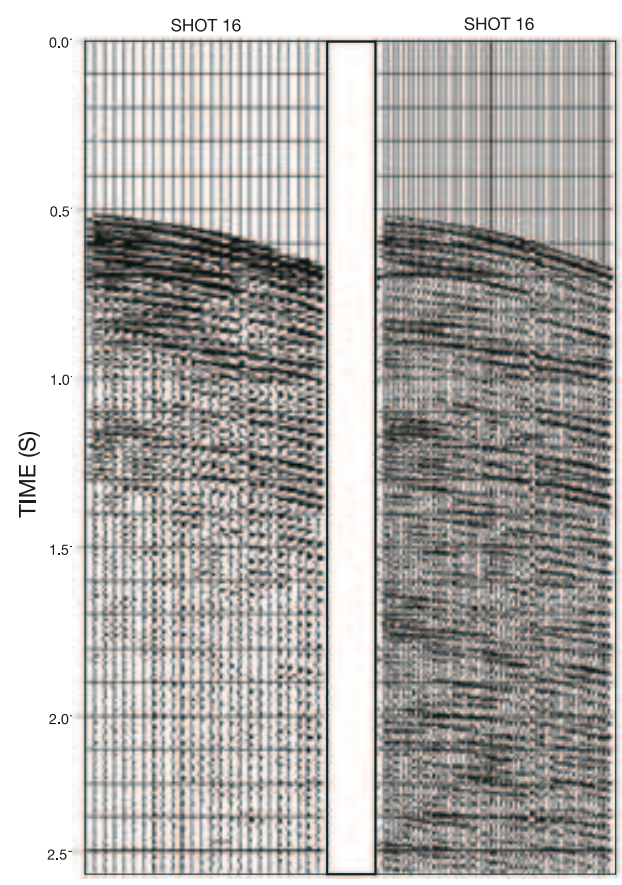

(a)

(b)

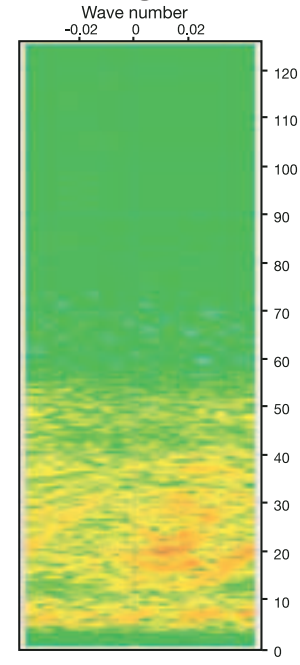

(C)

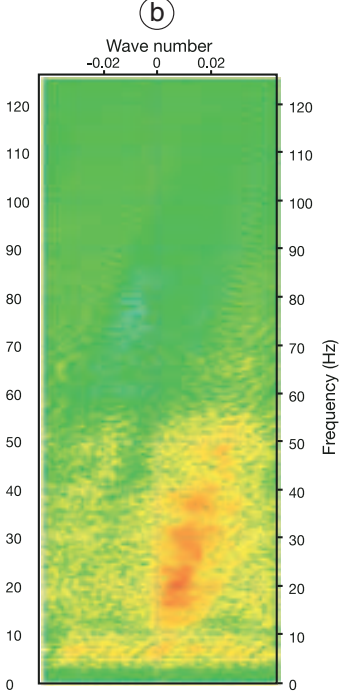

(d)
Fig. 3a-d. Raw CSP\#16 relative to seismic line NA12 (a) and its FK spectrum (c); Shot gather after trace interpolation (b) and its FK spectrum (d). Note that the increased number of traces (from 24 to 47 ) reduces the wrap around effect in the FK space. Wrap around starts at about $25 \mathrm{~Hz}$ on original data and at about $50 \mathrm{~Hz}$ after trace interpolation. 
recorded seismograms. The process of multiple energy estimation is controlled by the interpreter again by the analysis of the trace autocorrelation. An example of predictive deconvolution is reported in fig. 4a,b. After deconvolution we also applied a time and space variant bandpass filter (TVF) (Telford, 1990) to remove selectively the high and low frequency noise (also boosted by the deconvolution process) along the sections.

Multiple rejection was an important stage in our work. In addition to pre-stack and post-stack predictive deconvolution, another multiple suppression technique, based on FK dip filtering, was applied. FK multiple attenuation is a pro- cess combining: 1) velocity analysis; 2 ) forward Normal Move Out (NMO) correction; 3) FK dip filtering, and 4) inverse NMO correction. FK multiple attenuation offers a further gain in multiple energy suppression over stacking. The filter performs more quickly than other multiple suppression methods, and it is useful for multiple suppression on pre-stack data. In the FK domain, it is possible to discriminate between primary and multiple events, based on their different velocity. If the velocity analysis is done by picking the primary events, then NMO correction will flatten the primary reflections while the multiple reflections will be undercorrected. In such con-

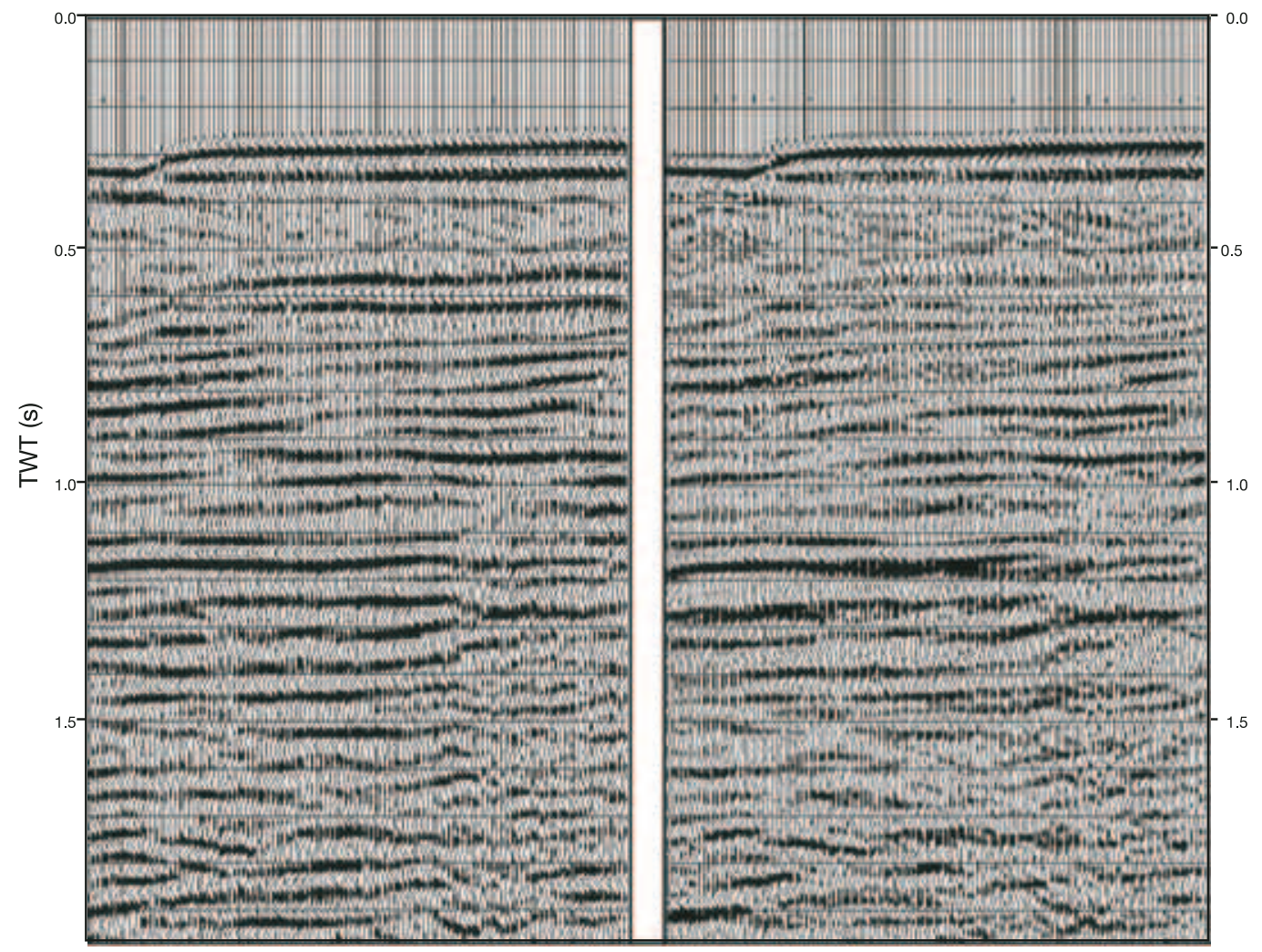

(a)

(b)

Fig. 4a,b. a) Part of seismic line NA20 with no deconvolution; a multiple of the sea bottom reflection is visible at $0.6 \mathrm{~s}$, TWT; b) the same data processed with predictive deconvolution using an operator length of $90 \mathrm{~ms}$ and a prediction lag of $40 \mathrm{~ms}$. Note that the multiple event at $0.6 \mathrm{~s}$ is strongly attenuated. 
dition, removal of multiple energy in the FK space consists of defining a narrow fan near the frequency axis. This fan will allow all primary reflectors to be passed (with infinite apparent velocity after NMO correction) and will attenuate the multiples. An example of FK Multiple attenuation is shown in fig. 5a-d.

A qualitatively high velocity analysis is a key for obtaining a good seismic stack. A correct velocity function will align all reflection hyperbole. Stacking NMO corrected CDP gathers will increase the $\mathrm{S} / \mathrm{N}$ ratio of the reflections by $(n)^{1 / 2}$, where $n$ is the trace fold. Stacking with the correct velocity function will also reduce the amplitude of coherent noise such as refractions, guided waves and multiples. Velocity analysis was made using the semblance function, $S(v, t)$ that is defined as a normalized cross-correlation

$$
S(v, t)=\frac{\sum_{t=\tau-d t}^{\tau+d t}\left|\sum_{x} p(x, t, v)\right|^{2}}{N \cdot \sum_{t=\tau-d t}^{\tau+d t}\left|\sum_{x} p(x, t, v)\right|^{2}}
$$

where $p(x, t, v)$ is the NMO corrected trace, $N$ is the number of traces in CDP, $t$ is the TWT, $v$ is

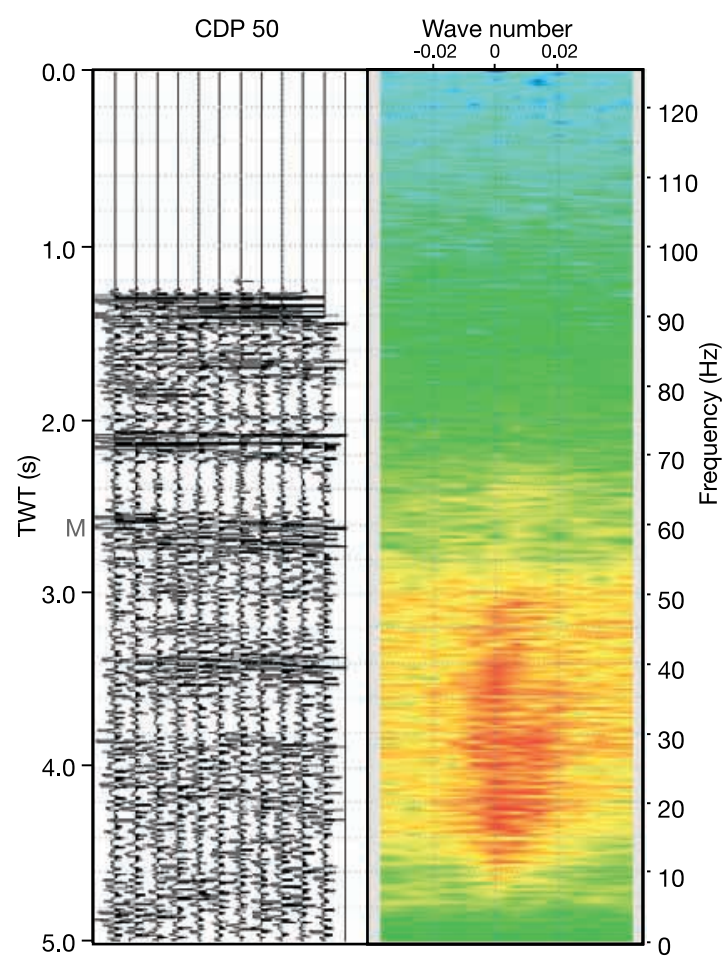

(a)

(b)

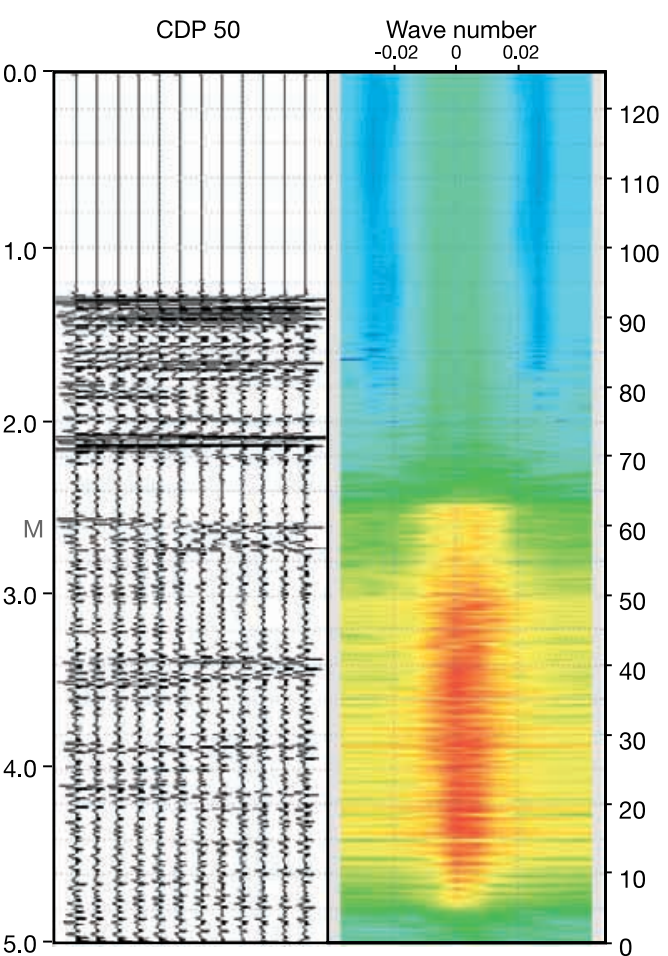

(C)

(d)

Fig. 5a-d. a) CDP gather \# 50 of seismic line NA08, with NMO correction applied. Note the presence of a seabottom multiple (M) reflection at $2.60 \mathrm{~s}$ TWT, characterized by a residual moveout not entirely removed by the NMO correction (which was finalised to primary events). b) FK spectrum of panel A; the primary reflectors are collapsed near the $\mathrm{F}$ axis while the multiple energy has a dip in the $k$ positive halfspace. c,d) CDP gather in the $(x, t)$ and $(f, k)$ space after filtering with a narrow «pass» fan in the FK space. Both graphs show a strong reduction of the energy associated with the $2.60 \mathrm{~s}$ TWT multiple reflection. 


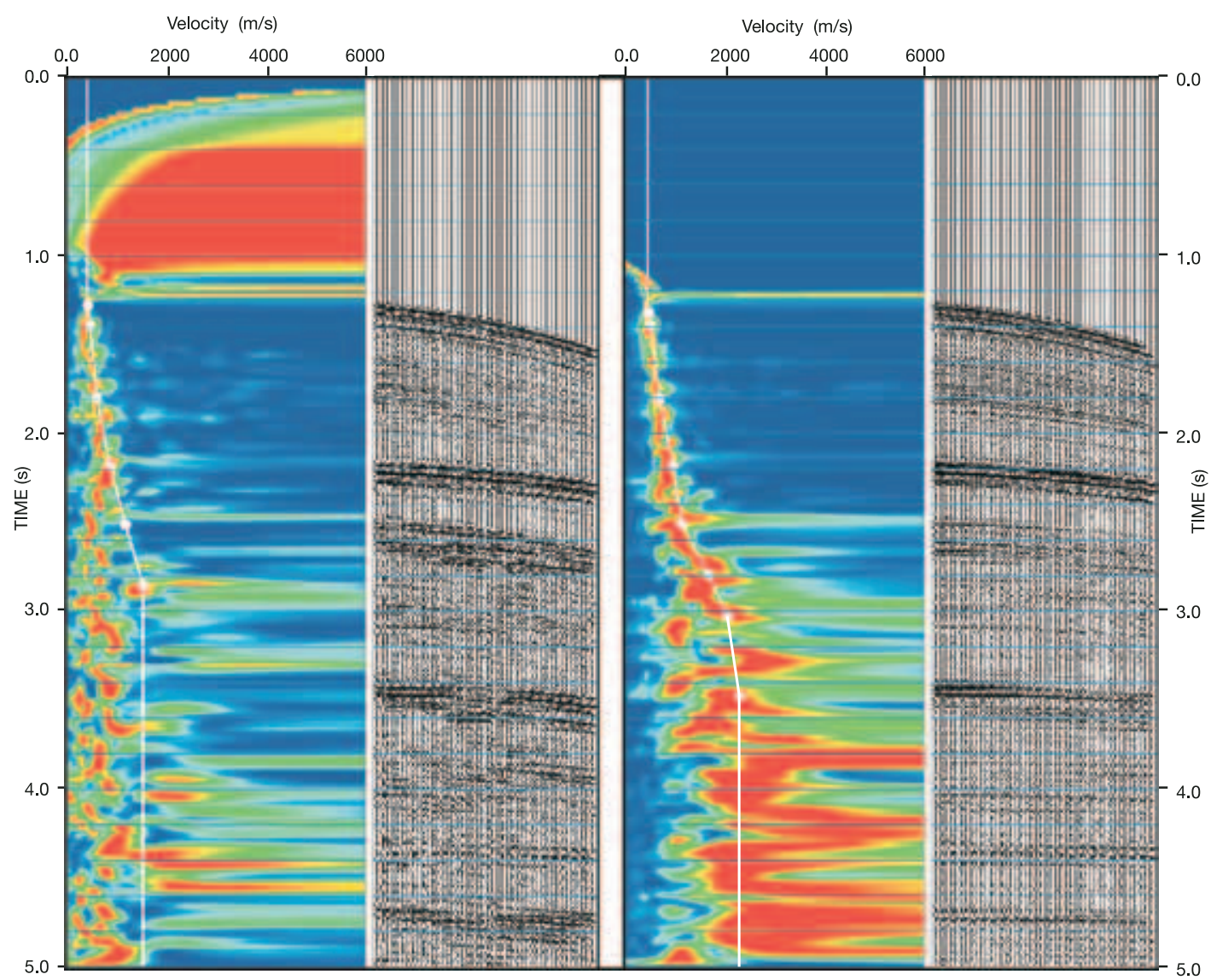

(a)

(b)

Fig. 6a,b. Semblance function for a selected CDP gather of seismic line NA05 before (a) and after (b) FK passprimary filtering, predictive deconvolution and residual static correction. Note the improved quality of the velocity spectrum after suppression of multiple reflections (leftmost peaks on the semblance graph), and the reduction of the energy associated to the multiple of the sea bottom at $2.4 \mathrm{~s}$ TWT on the seismic traces.

the velocity and $x$ is CDP spacing. Figure 6a shows a graph of $S(v, t)$ that is also referred to as «velocity spectrum». The points where the semblance values are higher generally indicate the best stacking velocity. Obviously, the process of picking the velocity function must be completely interactive; in other words the interpreter must have complete control of the process. Generally, the semblance graph improves after the application of other processes such as multiple attenuation, FK and bandpass filtering, residual static, etc. In fig. $6 a$, the ve- locity spectrum shows the presence of low velocity peaks at high TWT. These low velocities are unrealistic (because they are not consistent with respect to depth) and are linked to multiple events and/or to other types of disturbances, such as guided waves, etc. Figure $6 \mathrm{~b}$ shows the same spectrum as fig. 6a after noise attenuation processes. The improvement in the velocity spectrum is evident.

Our velocity functions were obtained using three or four cycles of velocity analysis and residual static corrections, before and after the application of noise reduction processes. This 
iterative cycle improves the quality of the velocity function. For marine data, it is easy to define a reference datum for static corrections, that generally coincides with the Mean Sea Level (MSL). Residual static corrections consisted of a cross-correlation procedure that evaluates the time shift due to source-receiver position at surface. Cross correlation between adjacent traces was calculated using the following formula:

$$
C_{p_{i} p_{i+1}}=\sum_{t} \sum_{i=1}^{n} p_{i}(t) \cdot p_{i+1}(t+\tau)
$$

where $p(t)$ is the seismic trace, $t$ is the time window length and $\tau$ is the lag time. The process creates time varying residual or trim statics within selected windows along the traces in a CDP gather. These windows must include the reflectors of interest and must exclude coherent noise (such as the multiples). The process is also useful for cleaning up a brute stack which will be used as model traces for external model correlation statics or for removing residual moveout before a brute stack. Trim statics are computed for each time window. After the statics are computed they are applied at each sample by interpolating the statics between the window centers above and below the sample. Figure 7a shows a NMO corrected CDP gather, relative to line NA08 before the application of residual static correction. There is a static shift between the first and the second part of the gather, well visible on the reflector at $1.5 \mathrm{~s}$ TWT. Such static shifts lead to degradation of the stack. After application of residual statics such shift was removed (fig. 7b).

As a final pre-stack process, we applied the Dip Moveout (DMO) correction (Yilmaz and Claerbout, 1980). DMO correction is a dipdependent, partial migration, applied to nonzero offset seismic data. After DMO correction, the data exhibit the same hyperbolic zero-offset trend for all offsets. This transformation from non hyperbolic offset to hyperbolic (zero) offset yields improved velocity estimates and higher lateral resolution, as well as a few other desirable side effects, such as the attenuation of coherent noise. Application of DMO to prestack data and time migration to post-stack data emulates a full pre-stack migration, with the advantage of being computationally faster.

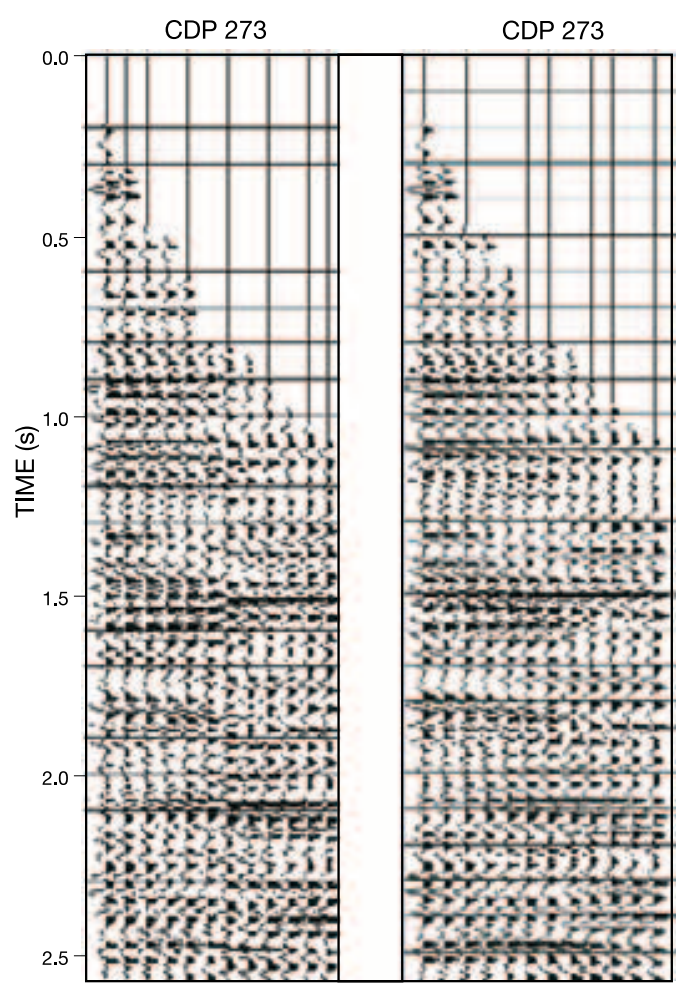

(a)

(b)

Fig. 7a,b. a) CDP gather 273 of seismic line NA19 after NMO correction; b) the same CDP after residual static correction.

After DMO, the stacked data were migrated in time, using two different algorithms: Stolt (Stolt, 1978) and Kirchhoff (Yilmaz, 1987) migration. Stolt FK migration migrates either common-offset or stacked seismic sections. It is computationally efficient and is very accurate for constant velocities, but has difficulty imaging steep dips in areas where there are large vertical or lateral velocity variations. This algorithm uses Stolt's stretching technique to account for vertical and lateral velocity variations. In more complex areas, where the reflectors have larger dips and complex velocity fields, such as in the GP, we used the Kirchhoff algorithm. Kirchhoff Time Migration performs a migration by applying a Green's function to each CDP location using a 


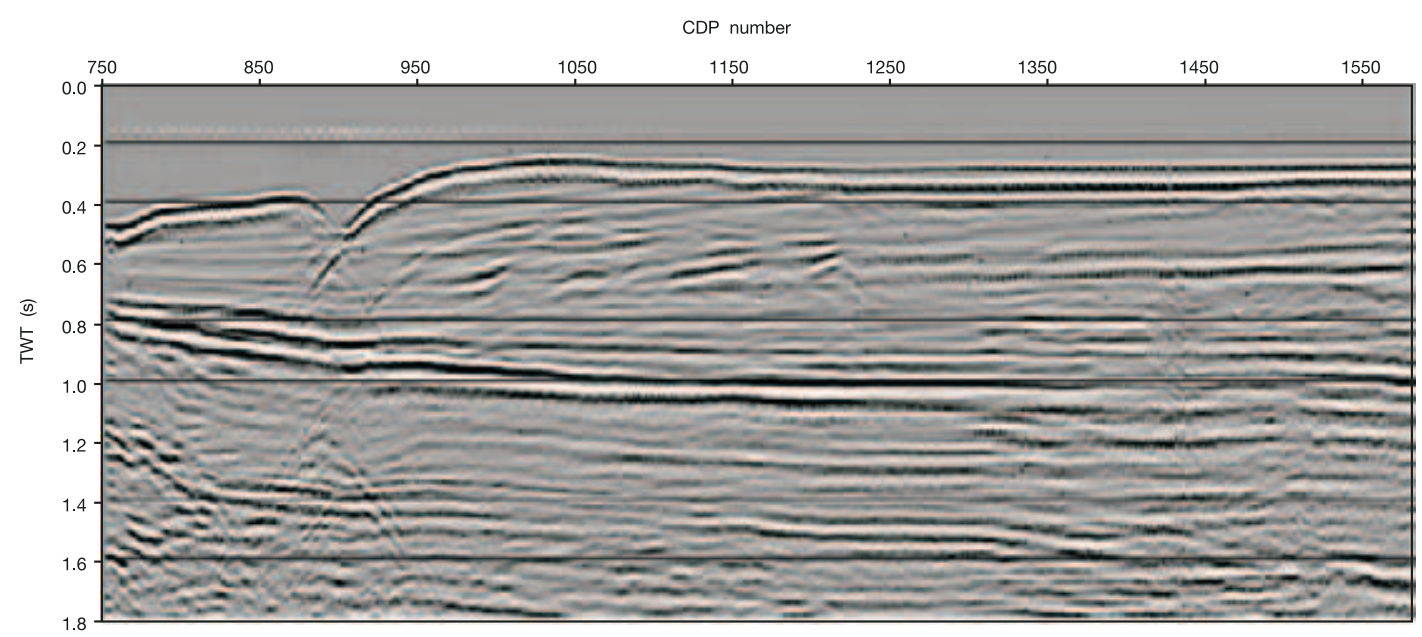

(a)

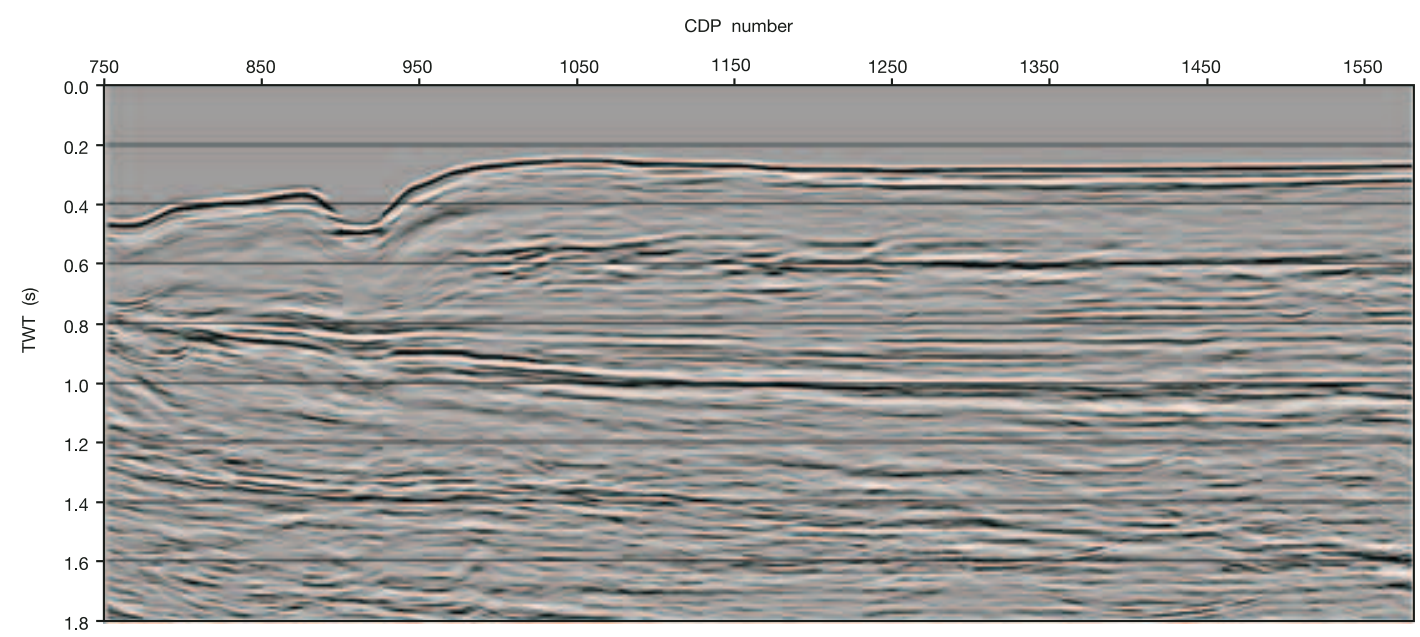

(b)

Fig. 8a,b. a) Part of seismic line NA20 (CDP 750-1575); b) the same line after the application of spiking deconvolution and pre-stack DMO and post-stack Kirchoff time migration. Refer to the text for explanation.

traveltime map. Traveltime maps relate the time from each surface location to a region of points in the subsurface. This migration uses a vertically and laterally variant RMS (Root Mean Square) velocity field, $V_{\mathrm{RMS}}(x, t)$, in time. This migration provides good handling of steep dips, up to 90 degrees, and of horizontal variation of velocity along the line. An example of seismic line processed with DMO correction and with
Kirchhoff migration is reported in fig. 8a,b. Migration collapsed the diffraction events in their apex and repositioned the seismic reflectors at their correct locations. This is particularly evident comparing the shape of the channel located between CDP 850-950.

The last process applied to the post-stacked data was the Frequency-Space (FX) deconvolution. FX deconvolution is a reliable multi- 
channel noise-reduction filter. It preserves the most dominant dipping energy while removing random noise or dips with very low energy (Cary and Upham, 1993). FX deconvolution produces a very natural looking result, with fewer artifacts than other methods (such as in FK and Radon filtering; Chase, 1992). For this reason, it is highly favoured for post-stack noise attenuation. Although the danger of rejecting weak coherent signal is always there for stacked data, in practice

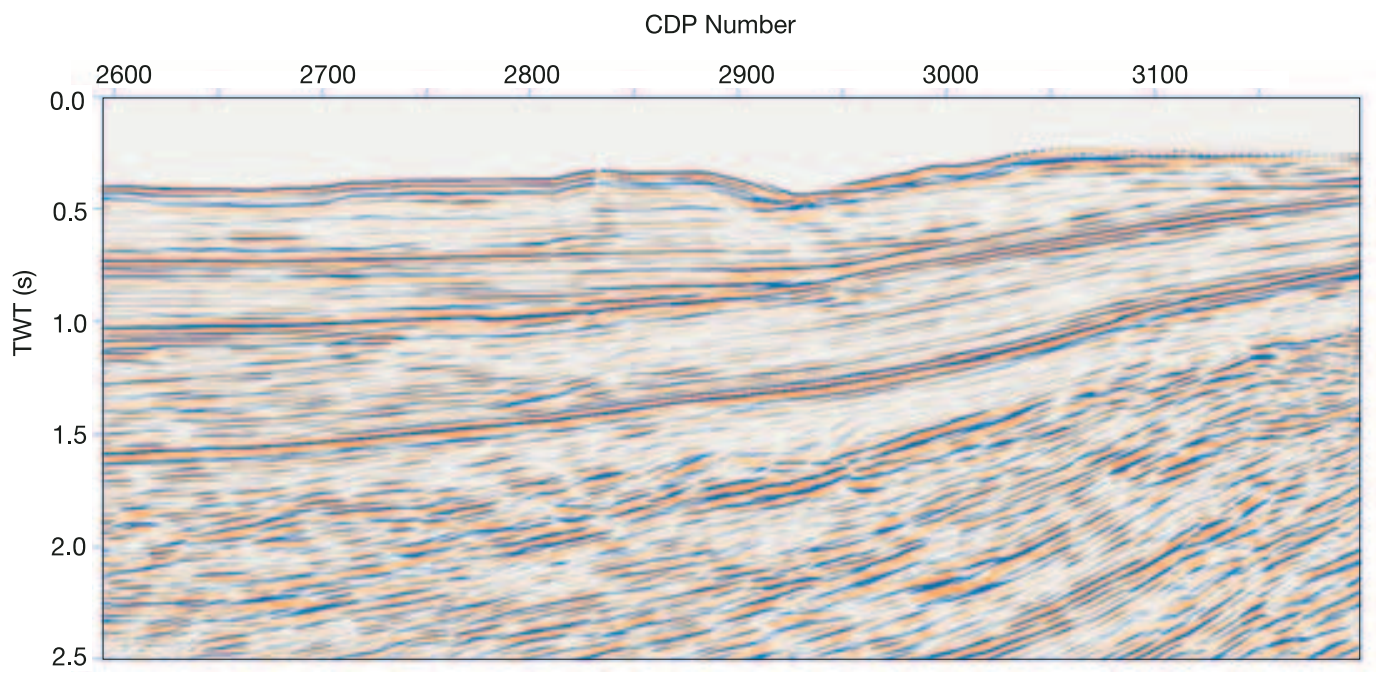

(a)

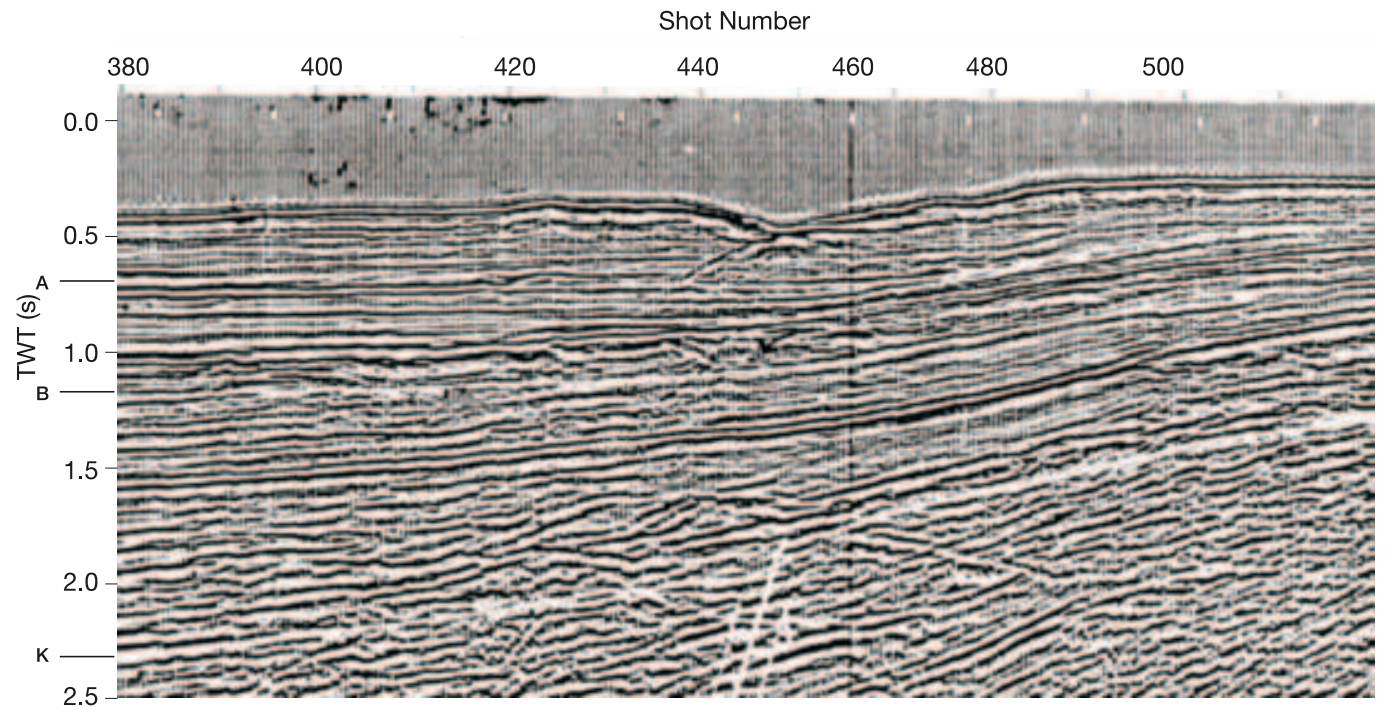

(b)

Fig. 9a,b. Comparison between the reprocessed seismic line and the section of Finetti and Morelli (1974). a) Seismic line NA09 (CDP 2590-3210) with the new processing sequence; b) the same line processed in 1974. Notice the slot that improved the $\mathrm{S} / \mathrm{N}$ ratio allows a clearer identification of reflectors $\mathrm{A}, \mathrm{B}$ and $\mathrm{K}$. 


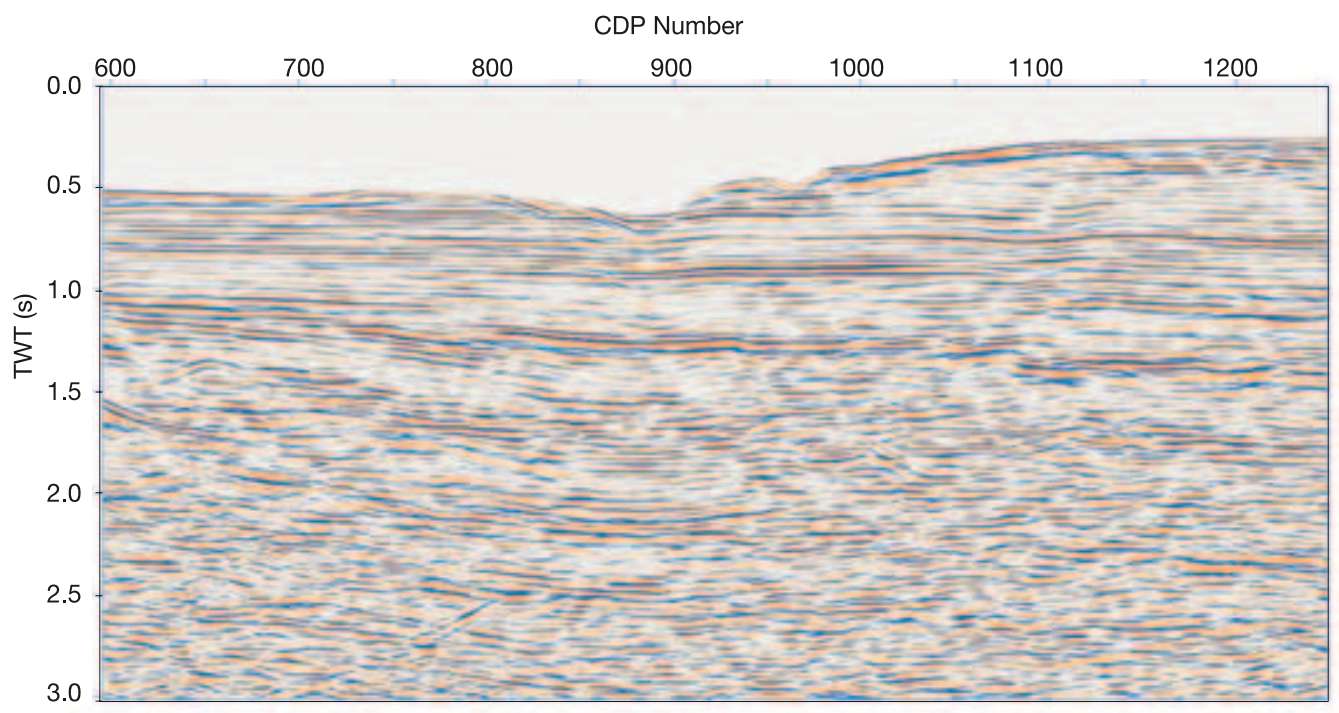

(a)

Shot Number

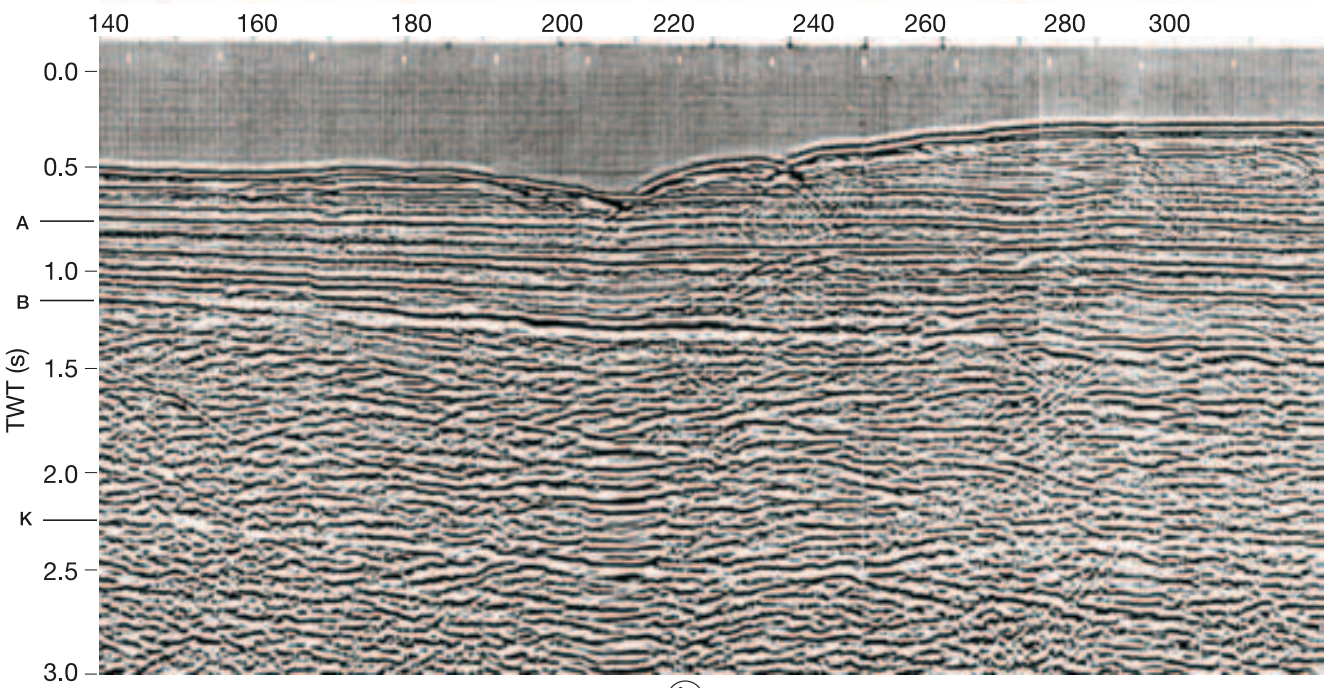

(b)

Fig. 10a,b. a) Seismic line NA19 (CDP 590-1250) with the new processing sequence; b) the same line processed in 1974. On the left side of the new section (CDP 1000-1200) reflector B of Finetti and Morelli (1974) is discontinuous and is probably affected by faults. Reflector $\mathrm{K}$ is also highly discontinuous and probably is placed at a different depth with respect to that inferred on the basis of the old data.

FX deconvolution is surprisingly robust. The FX deconvolution algorithm (Gulunay, 1986) applies a Fourier transform to each trace of an input ensemble, a complex, Wiener, unit prediction filter (Robinson and Treitel, 1964; Treitel, 1974) in distance for each frequency in a specified 


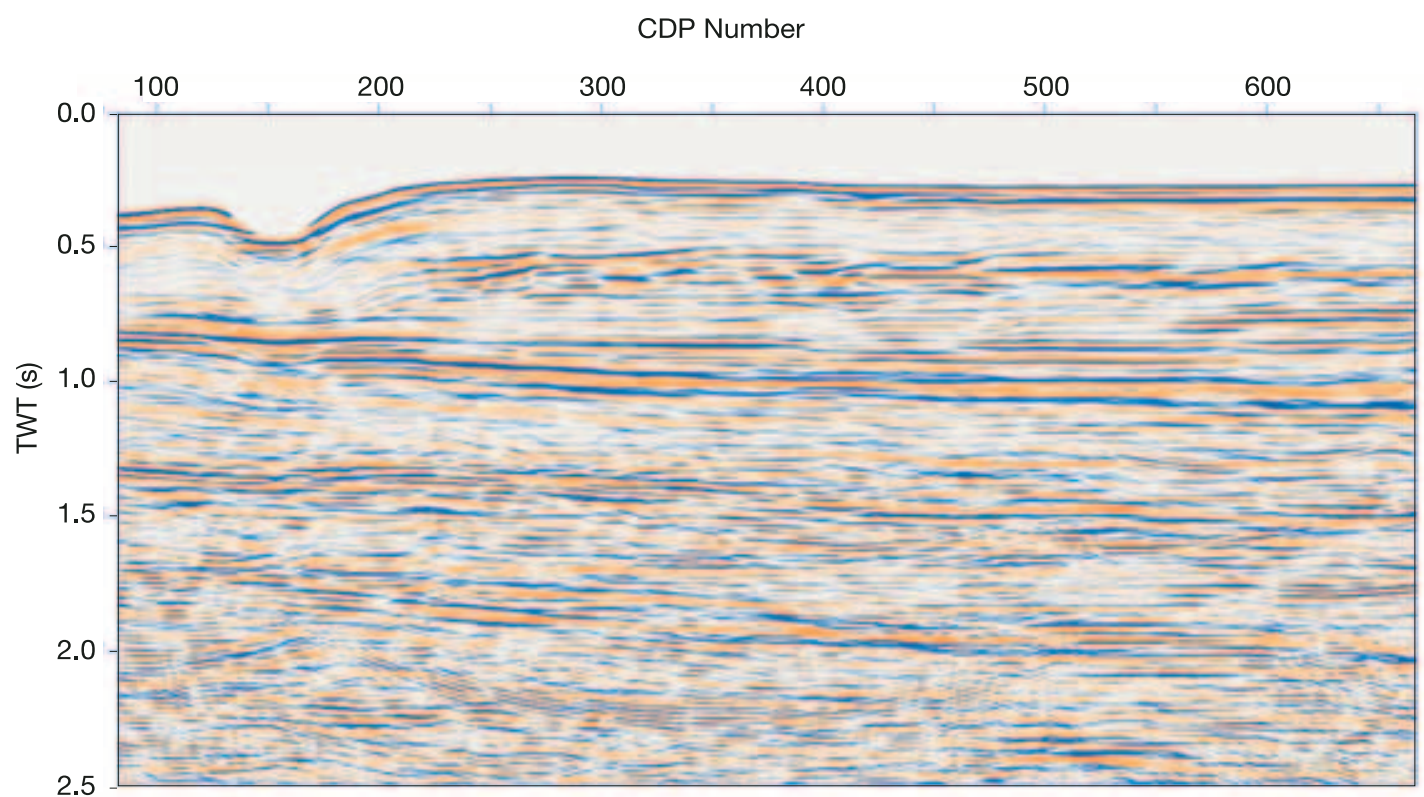

(a)

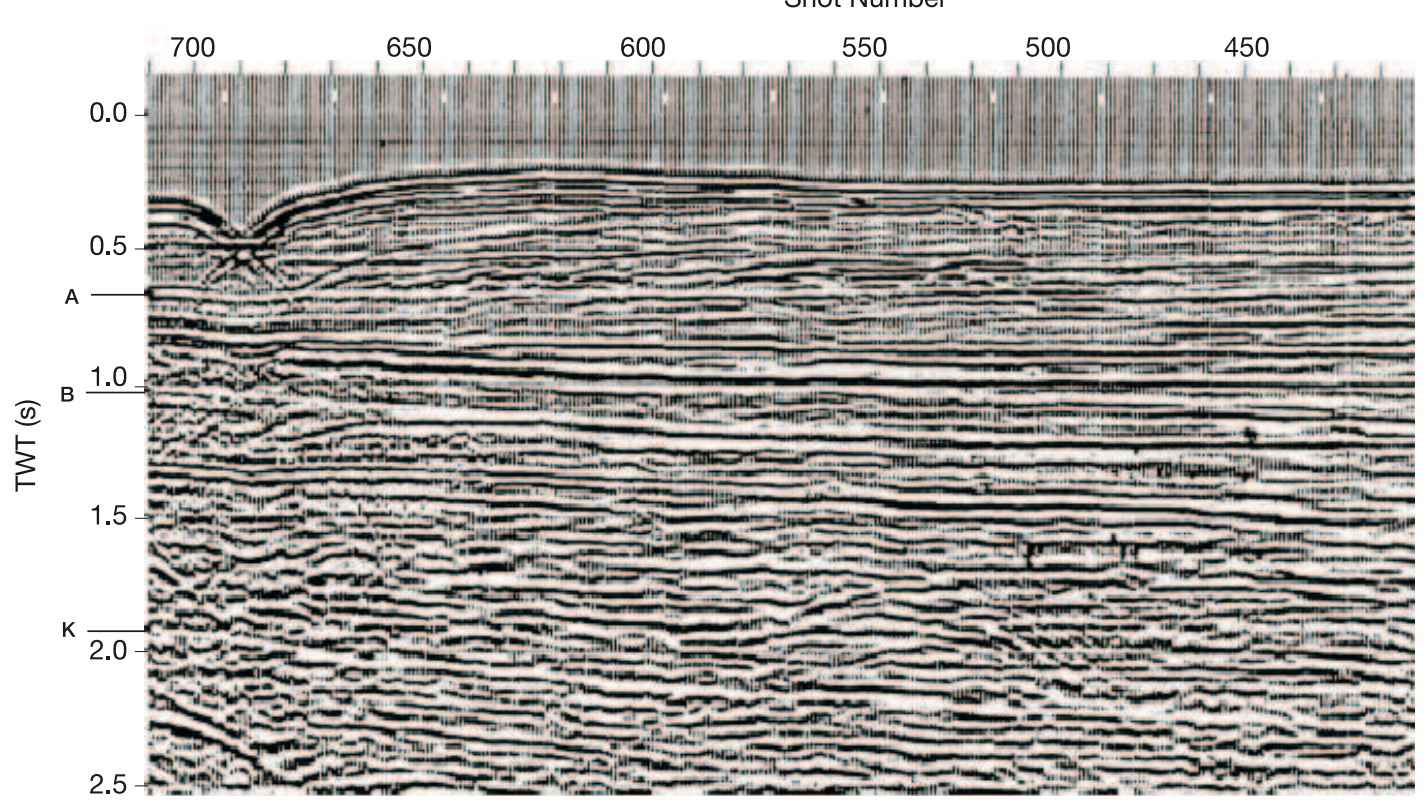

(b)

Fig. 11a,b. Comparison between the reprocessed seismic line and the old section data of 1974. a) Seismic line NA20 (CDP 50-660) with the new processing sequence; b) the same line processed in 1974. Position of reflectors $\mathrm{A}$ on the old data does not correspond to any reflector on the new seismic section. Reflector $\mathrm{K}$ can be followed more easily on the new data and its trend shows discrepancies with that outlined on the old data. 
range, and then inverse transforms each resulting in frequency trace back to the time domain. Each sample in the transformed data has both real and imaginary components. Events with similar dips appear as a sinusoidally complex signal along a given frequency slice. The output trace should have less random noise than the input.

\section{Discussion of results}

The study area shows an extremely variable seismic response. On relatively narrow distance, zones with excellent reflectivity and areas of low $\mathrm{S} / \mathrm{N}$ are found. The main reason of the signal decay is due to the massive presence of volcanic rocks and structures, alternating to the Middle and Late Quaternary and Pliocene series and producing a strong scattering of the seismic energy, especially in the GP. For this reason, the GP is characterized by a completely different seismic response, if compared to other parts of NB. On the old seismic sections of 1973 (Finetti and Morelli, 1974), the lines acquired in the GP were characterized by such a low $\mathrm{S} / \mathrm{N}$ ratio that it was virtually impossible to identify any geological structure below the very shallow Quaternary drape. This $\mathrm{S} / \mathrm{N}$ decay is due not only to the abundant presence of volcanites but also to a large number of fault fractures and other disturbances, such as volcanic bodies that cause diffuse diffraction and backscattering of the seismic energy thus limiting heavily the interpretability on the old unmigrated seismic sections. The $\mathrm{S} / \mathrm{N}$ ratio has been greatly improved on this new set of seismic sections allowing us to gain new information on the geological structure of this part of the bay.

Figures $9 \mathrm{a}, \mathrm{b}$ to $11 \mathrm{a}, \mathrm{b}$ report some comparisons between the new seismic sections and the old data. This comparison should not be seen as a criticism of the work done by Finetti and Morelli (1974) that was very advanced for the time, but as an example of the potential of such data, once reprocessed, of furnishing new geological information at low cost. In particular, comparison between the new and the old data show that the new sections are characterized by a much higher $\mathrm{S} / \mathrm{N}$ ratio. Diffraction hyperbole has been collapsed. Reverberations, ghosts and multiples have been removed or greatly attenuated, especially between the reflectors of interest, allowing us to follow them with more detail and with greater continuity. Furthermore, data resolution has been boosted by the reprocessing, allowing the interpreter to evaluate reflector position and continuity in more detail. For example, fig. 9a,b reports a part of seismic line NA09. The three major seismic reflectors, referred to as $\langle\mathrm{A} »,\langle\mathrm{~B} »$ and $\langle\mathrm{K} »$ in Finetti and Morelli (1974) and relative to major geological unconformities of the area, can be followed more easily on the new seismic sections. The same can be seen on line NA19 (fig. 10a,b) and on line NA20 (fig. 11a,b). The reinterpretation phase of such lines, that is already in a advanced stage, will therefore allow us to gain new hints on the structural setting of the bay, with the aim of exploring the connection between tectonics and volcanism.

\section{Acknowledgements}

The authors wish to thank the local scientific organizers of the Kyoto and Kobe meeting: Prof. H. Akihama, of Nihon University and Prof. M. Nakashima and his staff at Kyoto University for the tremendous effort in organizing the symposium; to Dr. A. Volpi, scientific attaché at the Italian Embassy in Japan and the Italian Embassy in Japan. Thanks are due to Prof. I. Finetti for the continuous encouragment and to GNV (National Volcanological Group) for financial support (G.N.V. grant to A.R.).

\section{REFERENCES}

AGIP (1982): Italia, carta magnetica, anomalie del campo residuo, scala 1:500000, foglio $H$ (Incontri grafici, F.1li Verga, Milano).

AGIP (1987): Geologia e Geofisica del Sistema Geotermico dei Campi Flegrei. Servizi Centrali per l'Eplorazione, SERG-MMESG, San Donato, pp. 19.

ALAM, A. and L. LASOCKI (1981): Slant stack and application, presented at the 41st Annual European Association for Exploration Geophysics Meeting.

Alessio, M., F. Bella, S. Improta, G. Belluomini, C. CORTESI and B. TURI (1974): University of Rome Carbon - 14 Dates XII, Radiocarbon, 16 (3), 358-367.

Andronico, D., G. CALderoni, R. Cioni, A. Sbrana, R. SULPIZIO and R. SANTACROCE (1995): Geological map 
of Somma-Vesuvius volcano, Period. Mineral., 64 (8), 77-78.

Andronico, D., R. Cioni, P. Marianelli and R. SANATCROCE (1996): Introduction to Somma-Vesuvius, in Vesuvius Decade Volcano, Workshop handbook, edited by R. SANTACROCE et al., 1-49.

ASTER, R.C. and R.P. MEYER (1988): Three-dimensional velocity structure and hypocenter distribution in the Campi Flegrei caldera, Italy, Tectonophysics, 149, 195-218.

BERrino, G., G. Corrado, G. LuONGO and B. TORO (1984): Ground deformation and gravity changes accompanying the 1982 Pozzuoli Uplift, Bull. Volcanol., 47 (2), 187 200.

BRACEWELL, R. N. (1965): The Fourier Transform and its Application (McGraw-Hill Book Co.), 108-120.

BRUNO, P.P.G. and A. RAPOLLA (1999): Study of sub-surface structure of Somma-Vesuvius (Italy) by seismic reflection data, J. Volcanol. Geotherm. Res., 92, I. 3-4, 373-387.

BRunO, P.P.G., G. CipPitelli and A. Rapolla (1998): Seismic study of the Mesozoic carbonate basement aroud Mt. Somma-Vesuvius volcanic complex (Italy), $J$. Volcanol. Geotherm. Res., 84, 311-322.

BRUNO, P.P.G., G. DE AlTERIIS and G. FlORIO (2002): The western undersea section of the Ischia volcanic complex (Italy, Tyrrhenian Sea) inferred by marine geophysical data, Geophys. Res. Lett., 29 (9), 57-1, 57-4.

CARY, P. and W. UPHAM (1993): Noise attenuation with 3D FXY deconvolution, in CSEG Convention Abstracts, 22-23.

CHASE, M. (1992): Random noise reduction by FXY prediction filtering, in 62nd SEG Convention Abstracts, 1152-1153.

Cinque, A., G. Rolandi and V. Zamaprelli (1985): L'estensione dei depositi marini olocenici nei Campi Flegrei in relazione alla Vulcano-Tettonica, Boll. Soc. Geol. It., 104, 327-348.

Civetta, L., C. Del Gaudio, S. DE Vita, M.A. Di Vito, G. Orsi, S. Petrazzuoli, G. Ricciardi and C. RicCO (1995): Volcanism and resurgence in the denselypopulated Campi Flegrei nested caldera, Period. Mineral., 64, 135-136.

De Stefano, M., G. Faella, M. Pecce and M. Damasco (1988): Caratterizzazione tipologica, danno e vulnerabilità del patrimonio edilizio di Pozzuoli: ipotesi di intervento, Rendiconto Convenzione di Ricerca Regione Campania-Università di Napoli: Bradisismo Fenomeni Connessi, 2, 1-63.

Diebold, J. B. and P.L. STOFFA (1981): The traveltime equation, tau- $p$ mapping and inversion of common midpoint data, Geophysics, 46, 238-254.

FINETTI, I. and C. MORELLI (1974): Esplorazione sismica a riflessione nei golfi di Napoli e Pozzuoli, Boll. Geofis. Teor. Appl., 16, 175-222.

Florio G., M. Fedi, F. CELla and A. RAPOlla (1997): The Campanian Plain and Phlegrean Fields: structural setting from potential field data, J. Volcanol. Geotherm. Res.,
91, 361-379.

GulunAY, N. (1986): FX decon and the complex weiner prediction filter for random noise reduction on stacked data, paper presented at the Society of Exploration Geophysicists 56th Annual International Meeting, Houston, TX.

LiRER, L., G. LUONGO and R. SCANDONE (1987): On the volcanological evolution of Campi Flegrei, Eos, Trans. Am. Geophys. Un., 68, 226-234.

LuOngo, G., E. Cubellis, F. OBrizzo and S.M. PetrazZOLI (1991): The mechanics of the Campi Flegrei resurgent caldera - a model, J. Volcanol. Geotherm. Res., 45, 161-172.

ORSI, G., S. DE VITA and M. DI VITO (1996): The restless, resurgent Campi Flegrei nested caldera (Italy): constraints on its evolution and configuration, J. Volcanol. Geotherm. Res., 74, 179-214.

PATACCA, E., R. SARTORI and P. ScAndone (1990): Tyrrhenian basin and Apenninic arcs: kinematics relations since late Tortonian times, Mem. Soc. Geol. It., 45, 425-451.

PEACOCK, K.L. and S. TREITEL (1969): Predictive deconvolution: theory and practive, Geophysics, 34, 155-169.

RoBINSON, E.A. and S. TREITEL (1964): Principles of digital filtering, Geophysics, 29, 395-404.

Rosi, M. and A. SBRANA (Editors) (1987): Phlegrean Fields, CNR Quad. Ric. Sci., 114 (9), 175.

SACCOROTTI, G., G. Ventura and G. Vilardo (2002): Seismic swarms related to diffusive processes: the case of Somma-Vesuvius volcano, Italy, Geophysics, 67 (1), 199-203.

SCANDONE, R., L.Giacomelli and P. GASPARINI (1993): Mount Vesuvius: 2000 years of volcanological observations, J. Volcanol. Geotherm. Res., 58, 5-25.

SCANDONE, R., F. BELluCCI, L. LIRER and G. RolANDI (1991): The structure of the Campanian Plain and the activity of Neapolitan Volcanoes, J. Volcanol. Geotherm. Res., 48, 1-31.

Sgrosso, I. (1998): Possibile evoluzione cinematica miocenica nell'orogene centro-sud-Appenninico, Boll. Soc. Geol. It., 117, 679-724,19 ff.

SHERIFF, R.E. and L.P. GELDART (1995): Exploration Seismology (Cambridge University Press II Ed.), pp. 419.

StolT, R.H. (1978): Migration by Fourier transform, Geophysics, 43, 23-48.

TELFORD, W. M., L.P. GELDARD and R.E. SHERIFF (1990): Applied Geophysics (Cambridge University PressCambridge), 299-302.

Treitel, S. (1974): The Complex Weiner Filter, Geophysics, 39 (2), 169-173.

Vilardo, G., G. De Natale, G. Milano and U. Coppa (1996): The seismicity of Mt. Vesuvius, Tectonophysics 261, 127-138.

YilmaZ, O. (1987): Seismic Data Processing, Society of Exploration Geophysics, Tulsa.

YilmaZ, O. and J.F. Claerbout (1980): Prestack partial migration, Geophysics, 45, 1753-1777. 